\title{
The 2009 L'Aquila earthquake coseismic rupture: open issues and new insights from 3D finite element inversion of GPS, InSAR and strong motion data
}

\author{
Manuela Volpe`, Simone Atzori, Antonio Piersanti, Daniele Melini
}

Istituto Nazionale di Geofisica e Vulcanologia, Rome, Italy

\author{
Article history \\ Received December 22, 2014; accepted May 15, 2015. \\ Subject classification: \\ Numerical approximations and analysis, Seismicity and tectonics, Dynamics and mechanics of faulting, Europe.
}

\begin{abstract}
We present a Finite Element inverse analysis of the static deformation field for the $M_{w}=6.3,2009$ L'Aquila earthquake, in order to infer the rupture slip distribution on the fault plane. An univocal solution for the rupture slip distribution has not been reached yet with negative impact for reliable hazard scenarios in a densely populated area. In this study, Finite Element computed Green's functions were implemented in a linear joint inversion scheme of geodetic (GPS and InSAR) and seismological (strong motion) coseismic deformation data. In order to fully exploit the informative power of our dense dataset and to honor the complexities of the real Earth, we implemented an optimized source model, represented by a fault plane subdivided in variable size patches, embedded in a high-resolution realistic three-dimensional model of the Apenninic seismo-tectonic setting, accounting for topographic reliefs and rheological heterogeneities deduced from local tomography. We infer that the investigated inversion domain contains two minima configurations in the solution space, i.e. a single-and a double-patch slip distribution, which are almost equivalent, so that the available datasets and numerical models are not able to univocally discriminate between them. Nevertheless our findings suggest that a two high-slip patch pattern is slightly favoured.
\end{abstract}

\section{Introduction}

The 2009 April $6 \mathrm{M}_{\mathrm{w}}=6.3 \mathrm{~L}$ 'Aquila earthquake is the largest event that struck the Abruzzi region in the last 300 years since the 1703 earthquake [Boschi et al. 2000]. The earthquake occurred at a hypocentral depth of $9.5 \mathrm{~km}$ and at a distance of about $2 \mathrm{~km}$ from L'Aquila city center [Chiarabba et al. 2009]. It was felt all over the central Italy, causing more than 300 casualties and extended damage.

The event was caused by the activation of the $\mathrm{Pa}$ ganica fault, a NW-SE oriented normal structure located east of L'Aquila in the central Apennines [EMERGEO Working Group 2010, Gori et al. 2012]. The rupture mechanism and source modeling have been widely studied and fault parameters have been retrieved: the fault strikes about $133^{\circ} \sim 144^{\circ}$ to the SE and dips about $45^{\circ} \sim 55^{\circ}$ to the SW [Chiarabba et al. 2009, Walters et al. 2009, Pondrelli et al. 2010], while seismic moment fluctuates from $1.6 \times 10^{18} \mathrm{Nm}$ to $3.7 \times 10^{18} \mathrm{Nm}$ [Dziewonski et al. 1981, Pondrelli et al. 2010, Scognamiglio et al. 2010], giving a moment magnitude between 6.08 and 6.31 .

In a previous paper [Volpe et al. 2012], we investigated the rupture slip distribution over a fault plane subdivided in equal size patches [Atzori et al. 2009] by linear inversion of GPS data [Anzidei et al. 2009, Cheloni et al. 2010], through a three-dimensional (3D) Finite Element (FE) modeling. Our findings predicted a source model featured by a concentrated slip distribution on the rupture plane, evidencing a single area of high slip release fully localized south-east of the hypocenter. This result was consistent with other studies [Atzori et al. 2009, Walters et al. 2009, Trasatti et al. 2011, Serpelloni et al. 2012]. The remarkable slip concentration was ascribed to the introduction of $3 \mathrm{D}$ complexities, whereas other authors [Cirella et al. 2009, Cheloni et al. 2010, Scognamiglio et al. 2010, Cirella et al. 2012] obtained a more heterogeneous slip distribution pattern assuming homogeneous or layered models. This suggests that slip complexity may be a modelistic artifact due to the simplification of the structural model.

Published papers provide different and partially contrasting models of the 2009 L'Aquila earthquake, pointing out an unexpectedly complex rupture propagation, and some issues, like small scale features of the slip distribution on the fault plane or the possibility of surface slip release, remain unsolved. There is a wide debate concerning the extension of the Paganica fault and the occurrence and location of primary surface faulting [EMERGEO Working Group 2010, Gori et al. 


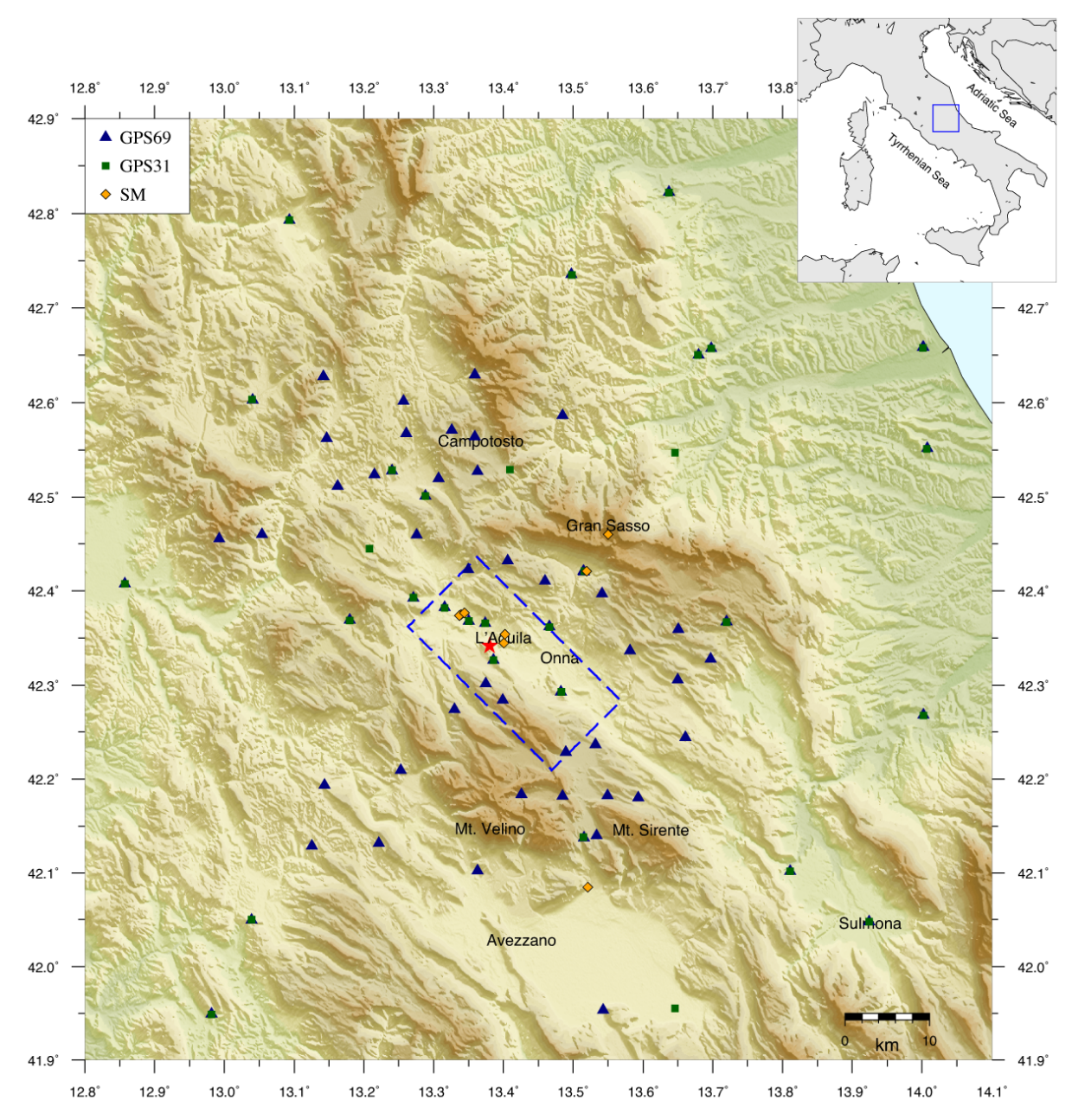

Figure 1. Overview map of the study area with the location of GPS and SM stations used in the present work. The red star indicates the main shock, while the blue dotted box is the surface projection of the fault plane.

2012, and references therein] and a better comprehension of the rupture process and the moment release is needed in order to constrain the extension of the seismogenic structure and accurately define the surface faulting pattern and the resulting hazard scenarios.

The present work represents an improvement in the 3D modeling of the 2009 event, since an advanced numerical approach as well as the most complete coseismic dataset are adopted, allowing us to further investigate the mechanism of the causative fault and detect small scale details of the slip release on the rupture plane. Implementing a realistic 3D structural model is a challenging and computationally demanding task, but its unique outcome represents fundamental information when earthquake scenarios are used for seismic hazard assessment and can have considerable impact on the retrieved source model. There are many examples in the literature showing the strong sensitivity of numerical simulations to $3 \mathrm{D}$ geological and rheological features, which turn out to provide more robust solutions and are essential to capture subtle but important local details which are intrinsically $3 \mathrm{D}$ effects [Komatitsch et al. 2004, Covellone and Savage 2012,
Magnoni et al. 2014]. On the contrary, homogeneous or 1D layered models, although clearly represent the fundamental starting base, can introduce numerical artifacts or trade-offs between structural and source parameters, as we inferred in past works [Volpe et al. 2011, 2012]. Definitely, accurate simulations are critical for quantitative hazard assessment.

In this respect, we improved our FE procedure with respect to the previous paper [Volpe et al. 2012], both from the modeling and the data sides, by implementing a more refined mesh of the L'Aquila basin and performing a joint inversion of GPS, InSAR and static displacements computed from strong motion (SM) data. Moreover, we adopted a variable patch fault model, as obtained by Atzori and Antonioli [2011] through an innovative algorithm used to retrieve the optimal fault subdivision in terms of model resolution [Menke 1989, Simons et al. 2002, Mothag et al. 2006]. It is worth noting that the adoption of such an uneven fault subdivision allows a more reliable modeling with respect to the use of equal size patches, which are likely to produce solutions that, although mathematically correct, can introduce spurious artifacts or lack in details [At- 
zori and Antonioli 2011]. In fact, the comparison between a regular fault subdivision [Atzori et al. 2009] and the uneven one [Atzori and Antonioli 2011] revealed an overestimated fault resolution at depth in the first case, while in the upper part of the fault a higher level of detail is achievable, which is lost by the a priori uniform subdivision.

The paper is organized as follows: Section 2 introduces experimental data used in the present work; Section 3 describes the FE model for the investigated area; Section 4 briefly resumes computational and methodological details; Section 5 presents results of the inversion procedures to obtain the slip distribution on the fault; in Section 6 we discuss the outcomes and provide our considerations; conclusive remarks are summarized in Section 7.

\section{Geodetic and seismological data}

The L'Aquila event is the best documented Italian earthquake and boasts a large quantity of observational data sets, both in terms of GPS measurements, SAR images and SM time series, which are expected to well constrain the fault parameters and the fault static slip distribution. In Figure 1 an overview map of the study area showing the location of GPS and SM stations used in the present work is displayed.

Our investigation uses GPS coseismic measurements from Devoti et al. [2012] and Cheloni et al. [2010], collected from different networks located in the Abruzzi region and its surroundings and managed by several agencies. Locations and offsets of data used in the present work are listed in Table 1.

Devoti et al. [2012] analyzed more than 100 GPS time series of continuous and discontinuous GPS stations, processed using two different softwares (Gamit [Herring et al. 2006] and Bernese [Beutler et al. 2007]) and then cross-checked to validate the geodetic solutions. We extracted a subset of 69 measurements from that dataset, since the remaining stations are not included within our simulation domain and, in any case, they are too far from the earthquake epicenter to be affected by detectable coseismic effects. Hereinafter this dataset will be referred to as GPS69. This is an upgrade of the GPS17 dataset used in our previous work [Volpe et al. 2012].

The Cheloni et al. [2010] dataset also uses observations from permanent and survey-style GPS sites, some of which are shared with Devoti et al. [2012] but differently processed: the GIPSY-OASIS software [Blewitt 2008] was used in this case to analyze data. From this dataset, we considered the 31 GPS stations included within our simulation domain. Hereinafter this dataset will be referred to as GPS31. This is the same GPS31 dataset used in Volpe et al. [2012].
Moreover, we also experimented with the full GPS dataset obtained by merging GPS69 and GPS31. The resulting not homogeneous GPS100 represents the most complete GPS dataset, where shared stations are counted as separate stations due to the different processing techniques.

The SAR dataset has been obtained from InSAR deformation maps acquired from ALOS (L-band, ascending orbit), COSMO-SkyMed (X-band, ascending) and ENVISAT (C-band, ascending and descending) satellites [Stramondo et al. 2011]. InSAR data have been processed with SARscape $\AA$ (from sarmap), using the SRTM digital elevation model to subtract the interferometric contribution given by topography. Details about the interferometric pairs used in this study are reported in Table 2. Displacements maps were sampled at the meshed domain surface, resulting in 88,411 punctual displacements $(25,701$ from ALOS; 7,855 from COSMO-SkyMed; 18,297 from ENVISAT ascending; 36,558 from ENVISAT descending).

Finally, we used SM data provided by Avallone et al. [2011], where the coseismic offsets from time series registered at selected near-field SM accelerometers (AQG, AQK, AQU, GSA and GSG) were computed. The displacement time series were obtained by a double integration of the accelerograms in the time domain, using a baseline correction aimed to retrieve the most stable trend in the static displacement [Avallone et al. 2011]. In order to increase the available dataset, we also considered displacement time series from three other SM sites (AQA, AQV and CLN). For the sake of consistency, we recalculated the coseismic offsets for all of the stations, obtaining the values reported in Table 3 as $\operatorname{SM}(a)$, perfectly comparable with the offsets from Avallone et al. [2011]. The SM displacements are consistent with GPS measurements, except for AQG and AQK, which show anomalously small horizontal components. For this reason, we took into account an alternate solution, obtained from a different integration procedure in the time domain, applying the baseline correction with a trial-and-error approach [Paolucci et al. 2008]. From the displacement time series, we calculated the static offsets labeled as $\mathrm{SM}(b)$ in Table 3. Hereinafter with the expression "SM inversion" we will refer to the inversion of the coseismic displacements computed from the seismic waveforms, not the inversion of the waveforms.

\section{The FE model}

We built a high-resolution 3D model $\sim 34 \mathrm{~km}$ thick, spanning a surface of about $11,385 \mathrm{~km}^{2}$ in the central Italy. The FE model was built up through the Cubit mesher, from Sandia National Laboratories (http: / / cubit. 
VOLPE ET AL.

\begin{tabular}{|c|c|c|c|c|c|}
\hline GPS69 & $\operatorname{lon}\left({ }^{\circ}\right)$ & lat $\left({ }^{\circ}\right)$ & $\mathrm{E}(\mathrm{mm})$ & $\mathbf{N}(\mathbf{m m})$ & $\mathrm{Up}(\mathbf{m m})$ \\
\hline ANAT & 13.55 & 42.18 & $-18.4 \pm 2.1$ & $10.8 \pm 3.3$ & $13.5 \pm 3.4$ \\
\hline AQRA & 13.37 & 42.37 & $6.7 \pm 1.2$ & $-55.3 \pm 2.2$ & $-117.4 \pm 2.2$ \\
\hline AQUI & 13.35 & 42.37 & $11.6 \pm 0.9$ & $-42.0 \pm 1.7$ & $-66.3 \pm 1.7$ \\
\hline ARAG & 13.46 & 42.41 & $47.8 \pm 2.1$ & $69.9 \pm 3.4$ & $70.0 \pm 3.4$ \\
\hline ASCO & 13.64 & 42.82 & $2.0 \pm 0.9$ & $6.8 \pm 1.6$ & $0.3 \pm 1.6$ \\
\hline ATRA & 14.01 & 42.55 & $6.1 \pm 0.7$ & $5.1 \pm 1.3$ & $1.7 \pm 1.3$ \\
\hline BANO & 13.58 & 42.34 & $52.1 \pm 1.1$ & $24.3 \pm 1.9$ & $6.8 \pm 1.9$ \\
\hline BOMI & 13.66 & 42.24 & $12.1 \pm 5.0$ & $1.2 \pm 7.2$ & $19.8 \pm 7.6$ \\
\hline BORB & 13.16 & 42.51 & $2.1 \pm 1.4$ & $0.8 \pm 2.6$ & $2.8 \pm 2.8$ \\
\hline BSPI & 13.65 & 42.31 & $19.6 \pm 1.5$ & $11.4 \pm 2.2$ & $1.6 \pm 2.4$ \\
\hline CADO & 13.48 & 42.29 & $-78.3 \pm 0.7$ & $62.3 \pm 1.3$ & $-152.0 \pm 1.7$ \\
\hline CAPI & 13.31 & 42.52 & $20.0 \pm 2.5$ & $-1.7 \pm 3.1$ & $-4.6 \pm 3.1$ \\
\hline CDRA & 13.72 & 42.37 & $23.2 \pm 0.9$ & $14.1 \pm 1.7$ & $-4.5 \pm 1.8$ \\
\hline CERT & 12.98 & 41.95 & $-6.1 \pm 0.7$ & $-1.9 \pm 1.3$ & $0.7 \pm 1.3$ \\
\hline COCA & 13.37 & 42.30 & $-17.4 \pm 5.6$ & $-2.3 \pm 6.3$ & $-76.3 \pm 6.3$ \\
\hline CPAG & 13.29 & 42.50 & $7.5 \pm 1.0$ & $0.5 \pm 1.8$ & $0.3 \pm 1.9$ \\
\hline CROG & 13.48 & 42.59 & $-0.6 \pm 1.9$ & $35.7 \pm 3.2$ & $3.1 \pm 3.5$ \\
\hline CTOS & 13.36 & 42.56 & $-15.0 \pm 3.5$ & $5.7 \pm 3.9$ & $-3.3 \pm 3.9$ \\
\hline INFN & 13.52 & 42.42 & $47.0 \pm 5.4$ & $50.9 \pm 9.5$ & $36.5 \pm 9.6$ \\
\hline INGP & 13.32 & 42.38 & $6.0 \pm 0.9$ & $-23.9 \pm 1.6$ & $-32.5 \pm 1.6$ \\
\hline ITRA & 14.00 & 42.66 & $5.1 \pm 3.3$ & $5.5 \pm 4.7$ & $-0.5 \pm 4.7$ \\
\hline ITTE & 13.68 & 42.65 & $8.0 \pm 1.0$ & $14.0 \pm 1.7$ & $-2.9 \pm 1.7$ \\
\hline LNGS & 13.51 & 42.42 & $47.6 \pm 0.9$ & $53.9 \pm 1.9$ & $27.4 \pm 1.9$ \\
\hline LNSS & 13.04 & 42.60 & $1.6 \pm 0.8$ & $1.2 \pm 1.4$ & $2.5 \pm 1.4$ \\
\hline MAMA & 13.25 & 42.21 & $-12.7 \pm 5.4$ & $-16.6 \pm 5.7$ & $2.9 \pm 5.7$ \\
\hline MICI & 13.05 & 42.46 & $11.9 \pm 5.9$ & $4.7 \pm 6.0$ & $-6.6 \pm 6.0$ \\
\hline MMAR & 13.36 & 42.10 & $2.3 \pm 7.4$ & $-6.5 \pm 7.5$ & $-17.3 \pm 7.5$ \\
\hline MOMO & 13.35 & 42.42 & $5.2 \pm 6.1$ & $-33.8 \pm 6.2$ & $-22.4 \pm 6.2$ \\
\hline MSNI & 13.36 & 42.53 & $13.2 \pm 1.7$ & $4.7 \pm 2.9$ & $-45.7 \pm 2.9$ \\
\hline MTRA & 13.24 & 42.53 & $5.1 \pm 1.1$ & $1.4 \pm 2.1$ & $1.1 \pm 2.1$ \\
\hline MTTO & 12.99 & 42.46 & $0.3 \pm 1.9$ & $0.8 \pm 3.1$ & $-7.2 \pm 3.2$ \\
\hline OCRA & 13.04 & 42.05 & $-7.1 \pm 0.8$ & $-5.0 \pm 1.6$ & $0.2 \pm 1.6$ \\
\hline OVIN & 13.53 & 42.14 & $-16.1 \pm 2.1$ & $18.7 \pm 3.4$ & $-1.0 \pm 3.6$ \\
\hline OVRA & 13.51 & 42.14 & $-6.2 \pm 1.2$ & $7.2 \pm 2.3$ & $-3.8 \pm 2.3$ \\
\hline PAGA & 13.47 & 42.36 & $-10.3 \pm 0.8$ & $-12.1 \pm 1.4$ & $-83.6 \pm 1.4$ \\
\hline POCA & 13.33 & 42.57 & $0.9 \pm 1.5$ & $-8.8 \pm 2.7$ & $-2.8 \pm 2.7$ \\
\hline PPEZ & 13.43 & 42.18 & $-9.2 \pm 4.9$ & $3.1 \pm 6.1$ & $-1.9 \pm 6.2$ \\
\hline PSCA & 13.12 & 42.13 & $-12.1 \pm 1.7$ & $-4.0 \pm 2.8$ & $-8.8 \pm 2.8$ \\
\hline PSIR & 13.59 & 42.18 & $-15.2 \pm 5.7$ & $11.3 \pm 7.2$ & $8.7 \pm 7.2$ \\
\hline QRTO & 13.40 & 42.28 & $-1.6 \pm 7.5$ & $31.0 \pm 7.6$ & $-110.3 \pm 7.6$ \\
\hline RAIA & 13.81 & 42.10 & $-1.1 \pm 0.9$ & $2.2 \pm 1.6$ & $-4.9 \pm 1.6$ \\
\hline RDCA & 13.49 & 42.23 & $-26.9 \pm 1.4$ & $28.6 \pm 2.3$ & $-31.3 \pm 2.4$ \\
\hline RENO & 13.09 & 42.79 & $1.7 \pm 1.0$ & $2.3 \pm 1.9$ & $-4.7 \pm 1.9$ \\
\hline RIET & 12.86 & 42.41 & $-2.4 \pm 0.8$ & $1.7 \pm 1.4$ & $3.1 \pm 1.4$ \\
\hline ROCA & 13.70 & 42.33 & $35.5 \pm 1.2$ & $18.5 \pm 2.0$ & $-2.6 \pm 2.0$ \\
\hline ROFA & 13.54 & 42.40 & $86.3 \pm 1.3$ & $66.4 \pm 2.2$ & $12.1 \pm 2.2$ \\
\hline ROIO & 13.39 & 42.33 & $10.4 \pm 0.7$ & $-8.8 \pm 1.2$ & $-115.2 \pm 1.3$ \\
\hline RSTO & 14.00 & 42.66 & $3.0 \pm 0.7$ & $6.7 \pm 1.2$ & $-3.4 \pm 1.2$ \\
\hline S260 & 13.26 & 42.60 & $3.2 \pm 1.9$ & $17.8 \pm 3.1$ & $-20.9 \pm 3.1$ \\
\hline SCRA & 14.00 & 42.27 & $3.8 \pm 1.2$ & $2.2 \pm 2.2$ & $-3.0 \pm 2.2$ \\
\hline SCRO & 13.15 & 42.56 & $8.5 \pm 4.6$ & $13.2 \pm 4.6$ & $1.9 \pm 4.6$ \\
\hline
\end{tabular}

Table 1 (continues on next page). 
THE 2009 L'AQUILA EARTHQUAKE: 3D FE INVERSION

\begin{tabular}{|c|c|c|c|c|c|}
\hline & $\operatorname{lon}\left({ }^{\circ}\right)$ & lat $\left({ }^{\circ}\right)$ & $\mathrm{E}(\mathbf{m m})$ & $\mathbf{N}(\mathbf{m m})$ & $\mathrm{Up}(\mathbf{m m})$ \\
\hline SCUO & 13.36 & 42.63 & $9.2 \pm 2.6$ & $19.6 \pm 3.8$ & $-7.8 \pm 3.8$ \\
\hline SELL & 13.18 & 42.37 & $-10.7 \pm 1.0$ & $-7.1 \pm 1.8$ & $11.1 \pm 1.8$ \\
\hline SLUC & 13.26 & 42.57 & $15.4 \pm 5.1$ & $10.2 \pm 5.3$ & $-21.9 \pm 5.3$ \\
\hline SMCO & 13.27 & 42.39 & $-2.5 \pm 0.9$ & $-9.8 \pm 1.6$ & $5.9 \pm 1.8$ \\
\hline SMRA & 13.92 & 42.05 & $-0.9 \pm 1.2$ & $3.4 \pm 2.3$ & $-1.6 \pm 2.3$ \\
\hline SROT & 13.14 & 42.63 & $5.3 \pm 8.4$ & $12.4 \pm 8.4$ & $-7.8 \pm 8.4$ \\
\hline SSMF & 13.22 & 42.13 & $-0.6 \pm 4.9$ & $-13.0 \pm 5.0$ & $27.4 \pm 5.0$ \\
\hline SSTS & 13.65 & 42.36 & $38.8 \pm 1.4$ & $30.0 \pm 2.3$ & $-11.5 \pm 2.3$ \\
\hline STAB & 13.41 & 42.43 & $20.3 \pm 1.3$ & $43.1 \pm 2.2$ & $-0.9 \pm 2.2$ \\
\hline TARI & 13.28 & 42.46 & $4.7 \pm 1.3$ & $-4.2 \pm 2.3$ & $10.9 \pm 2.8$ \\
\hline TERA & 13.70 & 42.66 & $7.4 \pm 1.1$ & $11.3 \pm 2.1$ & $-4.0 \pm 2.1$ \\
\hline TNER & 13.53 & 42.24 & $-40.5 \pm 3.4$ & $35.1 \pm 4.4$ & $-25.9 \pm 4.4$ \\
\hline TORN & 13.33 & 42.27 & $-14.9 \pm 4.2$ & $-11.0 \pm 4.8$ & $415.5 \pm 4.8$ \\
\hline TRAS & 13.54 & 41.95 & $0.8 \pm 6.1$ & $8.3 \pm 6.1$ & $-21.2 \pm 6.1$ \\
\hline VCRA & 13.50 & 42.73 & $4.2 \pm 0.9$ & $8.1 \pm 1.7$ & $-0.2 \pm 1.7$ \\
\hline VPEZ & 13.48 & 42.18 & $-16.8 \pm 4.7$ & $0.8 \pm 6.0$ & $-12.8 \pm 6.0$ \\
\hline VVRI & 13.14 & 42.19 & $-11.0 \pm 3.7$ & $-7.6 \pm 3.8$ & $-87.8 \pm 3.8$ \\
\hline SP30 & 13.21 & 42.52 & $11.2 \pm 20.0$ & $10.4 \pm 20.0$ & $4.3 \pm 20.0$ \\
\hline GPS31 & $\operatorname{lon}\left({ }^{\circ}\right)$ & lat $\left(^{\circ}\right)$ & $\mathrm{E}(\mathbf{m m})$ & $\mathbf{N}(\mathbf{m m})$ & $\mathrm{Up}(\mathbf{m m})$ \\
\hline AQRA & 13.37 & 42.37 & $5.2 \pm 0.8$ & $-63.2 \pm 1.0$ & $-114.1 \pm 3.6$ \\
\hline AQUI & 13.35 & 42.37 & $11.0 \pm 0.7$ & $-46.5 \pm 0.8$ & $-71.1 \pm 2.8$ \\
\hline ASCO & 13.64 & 42.82 & $1.4 \pm 0.6$ & $4.6 \pm 0.7$ & $-0.4 \pm 2.5$ \\
\hline ATRA & 14.00 & 42.55 & $6.4 \pm 0.5$ & $2.3 \pm 0.7$ & $2.6 \pm 2.3$ \\
\hline САТО & 13.41 & 42.53 & $2.2 \pm 0.4$ & $14.0 \pm 0.5$ & $-0.7 \pm 1.9$ \\
\hline CDRA & 13.72 & 42.37 & $25.6 \pm 0.5$ & $10.7 \pm 0.5$ & $-0.8 \pm 1.9$ \\
\hline CERT & 12.98 & 41.95 & $-6.7 \pm 0.5$ & $-5.5 \pm 0.6$ & $-0.7 \pm 2.0$ \\
\hline INFN & 13.52 & 42.42 & $56.8 \pm 1.2$ & $60.5 \pm 1.5$ & $17.2 \pm 1.8$ \\
\hline INGP & 13.32 & 42.38 & $5.3 \pm 0.6$ & $-30.1 \pm 0.7$ & $-24.4 \pm 2.4$ \\
\hline ITTE & 13.68 & 42.65 & $8.8 \pm 0.9$ & $10.5 \pm 1.1$ & $1.4 \pm 3.7$ \\
\hline LNSS & 13.04 & 42.60 & $0.9 \pm 0.3$ & $-2.4 \pm 0.4$ & $0.8 \pm 1.4$ \\
\hline MTRA & 13.24 & 42.53 & $3.6 \pm 0.4$ & $-1.9 \pm 0.5$ & $-1.5 \pm 1.9$ \\
\hline OCRA & 13.04 & 42.05 & $-8.6 \pm 0.8$ & $-7.3 \pm 1.0$ & $2.2 \pm 3.6$ \\
\hline OTRA & 13.65 & 41.95 & $-1.0 \pm 0.7$ & $0.8 \pm 0.8$ & $0.6 \pm 2.7$ \\
\hline OVRA & 13.51 & 42.14 & $-6.5 \pm 0.8$ & $4.0 \pm 0.9$ & $-4.1 \pm 3.4$ \\
\hline PAGA & 13.47 & 42.36 & $-11.3 \pm 0.7$ & $-17.4 \pm 0.9$ & $-89.9 \pm 3.1$ \\
\hline RAIA & 13.81 & 42.10 & $-0.7 \pm 0.6$ & $-0.5 \pm 0.7$ & $0.6 \pm 2.5$ \\
\hline RENO & 13.09 & 42.79 & $0.6 \pm 0.4$ & $-0.5 \pm 0.4$ & $-4.2 \pm 1.6$ \\
\hline RIET & 12.86 & 42.41 & $-4.5 \pm 0.4$ & $-3.0 \pm 0.5$ & $0.9 \pm 1.6$ \\
\hline RSTO & 14.00 & 42.67 & $4.5 \pm 0.6$ & $4.0 \pm 0.7$ & $-0.7 \pm 2.4$ \\
\hline SCRA & 14.00 & 42.27 & $5.6 \pm 0.4$ & $-0.8 \pm 0.5$ & $1.3 \pm 1.9$ \\
\hline SMRA & 13.92 & 42.05 & $0.8 \pm 0.4$ & $0.3 \pm 0.5$ & $-7.3 \pm 1.7$ \\
\hline TERA & 13.70 & 42.66 & $8.8 \pm 0.5$ & $10.2 \pm 0.6$ & $2.1 \pm 2.1$ \\
\hline TERM & 13.21 & 42.44 & $-1.3 \pm 0.4$ & $-8.2 \pm 0.4$ & $-0.8 \pm 1.6$ \\
\hline TOSS & 13.65 & 42.55 & $19.5 \pm 0.5$ & $20.5 \pm 0.7$ & $1.4 \pm 2.3$ \\
\hline VCRA & 13.50 & 42.73 & $2.3 \pm 0.5$ & $6.4 \pm 0.6$ & $-2.1 \pm 2.3$ \\
\hline CADO & 13.48 & 42.29 & $-81.3 \pm 1.4$ & $65.7 \pm 1.8$ & $-164.7 \pm 6.3$ \\
\hline CPAG & 13.29 & 42.50 & $2.9 \pm 2.5$ & $-1.9 \pm 2.8$ & $11.6 \pm 10.9$ \\
\hline ROIO & 13.39 & 42.33 & $11.0 \pm 1.4$ & $-12.2 \pm 1.8$ & $-123.7 \pm 6.2$ \\
\hline SELL & 13.18 & 42.37 & $-9.6 \pm 2.2$ & $-6.1 \pm 2.7$ & $10.1 \pm 9.7$ \\
\hline SMCO & 13.27 & 42.39 & $0.1 \pm 2.4$ & $-11.1 \pm 3.0$ & $19.7 \pm 11.0$ \\
\hline
\end{tabular}

Table 1 (continued from previous page). Location and coseismic displacements, for each component, for GPS data used in the present work. The datasets are taken from Devoti et al. [2012] (GSP69) and Cheloni et al. [2010] (GPS31). 


\begin{tabular}{llccc} 
Satellite (orbit pass) & \multicolumn{2}{c}{ Interferogram pair } & Look angle & Perpendicular baseline \\
\hline Alos (ascending) & $20 / 07 / 2008$ & $22 / 04 / 2009$ & Right $32^{\circ}$ & $322 \mathrm{~m}$ \\
CosmoSkymed (ascending) & $04 / 04 / 2009$ & $12 / 04 / 2009$ & Right $35.9^{\circ}$ & $435 \mathrm{~m}$ \\
Envisat (ascending) & $11 / 03 / 2009$ & $15 / 04 / 2009$ & Right $23^{\circ}$ & $237 \mathrm{~m}$ \\
Envisat (descending) & $27 / 04 / 2008$ & $12 / 04 / 2009$ & Right 23 & $41 \mathrm{~m}$ \\
\hline
\end{tabular}

Table 2. Acquisition dates and interferometric parameters of the image pairs used in this study.

\begin{tabular}{|c|c|c|c|c|c|c|c|c|}
\hline & \multirow[b]{2}{*}{$\operatorname{lon}\left({ }^{\circ}\right)$} & \multirow[b]{2}{*}{ lat $\left(^{\circ}\right)$} & \multicolumn{3}{|c|}{$\operatorname{SM}(a)^{\star}$} & \multicolumn{3}{|c|}{$\operatorname{SM}(b)$} \\
\hline & & & $\mathbf{N}(\mathbf{c m})$ & $\mathrm{E}(\mathrm{cm})$ & $\mathrm{Up}(\mathrm{cm})$ & $\mathbf{N}(\mathbf{c m})$ & $\mathrm{E}(\mathrm{cm})$ & $\mathrm{Up}(\mathrm{cm})$ \\
\hline AQA & 13.337 & 42.375 & $-0.73 \pm 0.26$ & $2.55 \pm 0.24$ & $-3.40 \pm 0.14$ & $-3.36 \pm 0.26$ & $2.71 \pm 0.24$ & $-2.97 \pm 0.13$ \\
\hline AQG & 13.337 & 42.375 & $0.04 \pm 0.28$ & $0.15 \pm 0.22$ & $-0.47 \pm 0.21$ & $-1.80 \pm 0.28$ & $0.03 \pm 0.22$ & $-2.38 \pm 0.12$ \\
\hline AQK & 13.400 & 42.344 & $0.18 \pm 0.61$ & $-0.04 \pm 0.75$ & $-15.72 \pm 0.21$ & $-0.72 \pm 0.61$ & $-1.75 \pm 0.75$ & $-15.36 \pm 0.18$ \\
\hline AQU & 13.402 & 42.353 & $-3.88 \pm 0.39$ & $0.48 \pm 0.56$ & $-14.98 \pm 0.29$ & $-5.41 \pm 0.39$ & $0.78 \pm 0.47$ & $-14.89 \pm 0.30$ \\
\hline AQV & 13.347 & 42.378 & $-0.75 \pm 0.32$ & $-0.06 \pm 0.26$ & $-3.49 \pm 0.17$ & $-3.71 \pm 0.24$ & $1.78 \pm 0.25$ & $-3.65 \pm 0.16$ \\
\hline CLN & 13.520 & 42.085 & $-0.07 \pm 0.17$ & $0.13 \pm 0.14$ & $-0.10 \pm 0.11$ & $0.27 \pm 0.17$ & $-0.08 \pm 0.14$ & $-0.13 \pm 0.12$ \\
\hline GSA & 13.520 & 42.422 & $3.97 \pm 0.18$ & $5.64 \pm 0.20$ & $1.06 \pm 0.12$ & $4.51 \pm 0.14$ & $4.83 \pm 0.20$ & $1.71 \pm 0.12$ \\
\hline GSG & 13.548 & 42.460 & $2.09 \pm 0.16$ & $3.14 \pm 0.11$ & $0.30 \pm 0.07$ & $2.05 \pm 0.16$ & $3.18 \pm 0.11$ & $0.84 \pm 0.06$ \\
\hline
\end{tabular}

Table 3. Coseismic offsets, for each component, computed at SM stations, using two different displacement time series processing. $\left(^{*}\right)$ Compare to Avallone et al. [2011]: AQG $0.04 \pm 0.29,0.10 \pm 0.21,-0.52 \pm 0.10$; AQK $0.15 \pm 0.44,-0.16 \pm 1.11,-15.57 \pm 0.23$; AQU $-3.82 \pm 0.43$, $0.39 \pm 0.53,-15.02 \pm 0.20 ;$ GSA $4.06 \pm 0.08,5.57 \pm 0.24,1.15 \pm 0.11$; GSG $2.21 \pm 0.08,3.23 \pm 0.07,0.34 \pm 0.14$.

sandia.org), a full-featured software toolkit for geometry preparation and robust generation of $2 \mathrm{D}$ and $3 \mathrm{D}$ complex FE meshes [Casarotti et al. 2008]. Real surface topography with $500 \mathrm{~m}$ spatial resolution, obtained from the Shuttle Radar Topography Mission (SRTM) $90 \mathrm{~m}$ digital elevation data [Farr et al. 2007], was incorporated within the model.

The volume was discretized using 20-nodes brick elements: the generated unstructured mesh contains $5,142,895$ elements, resulting in 20,816,823 nodes. An image of the meshed domain is shown in Figure 2.

The topographic surface was meshed using a geometry-adapting sizing function, which automatically generates a mesh sizing function based on geometric properties of the model. This allows unstructured meshing schemes to generate an optimally resolved mesh with element size varying smoothly throughout the domain. As a result, regions of relatively high complexity will have a finer mesh size, while regions of relatively low complexity will have a coarser mesh size. The obtained surface mesh follows the topographic profile, with an average element size of about 600-900 $\mathrm{m}$.

Under the topographic surface, within the first 17 $\mathrm{km}$ of the crust, the horizontal element size was biased from $150 \mathrm{~m}$ to about $2 \mathrm{~km}$, using the paving meshing algorithm, which allows for easy transitions between dissimilar sizes of elements and element size variations based on sizing functions. The vertical size was fixed at $450 \mathrm{~m}$. At depths greater than $17 \mathrm{~km}$, the same mesh scheme was used in combination with an appropriate specified bias sizing function but, for computational reasons, a coarser mesh was generated, having horizontal element size biased from $900 \mathrm{~m}$ to $4 \mathrm{~km}$ and vertical size fixed at $1 \mathrm{~km}$. A top view of the 0 and $17 \mathrm{~km}$ surfaces is provided in Figure S1 of the supporting material, where the mesh bias is evidenced.

The model is governed by elastic behaviour. A heterogeneous rheology was implemented and the elastic parameters were deduced from $v_{p}$ and $v_{p} / v_{s}$ travel time tomographic models [Chiarabba et al. 2010, Di Stefano et al. 2011]. The nearest neighbor interpolation method was used to include tomography within the simulation domain: accordingly, each mesh element is related to the closest tomographic point, not considering other neighboring points. The density profile has been approximated as a quadratic equation relating density to vp, deduced by fitting a gravity model [Magnoni et al. 2014]. In Figure 2 the compressional wave velocity from the implemented tomography is displayed.

Up to $15 \mathrm{~km}$ depth, a local high-resolution tomography [Di Stefano et al. 2011], defined on a 3D grid having node spacing of $5 \mathrm{~km}$ horizontally and $2 \mathrm{~km}$ vertically, was considered. From $17 \mathrm{~km}$ depth to the bottom of the domain a coarser model [Chiarabba et al. 2010] was 


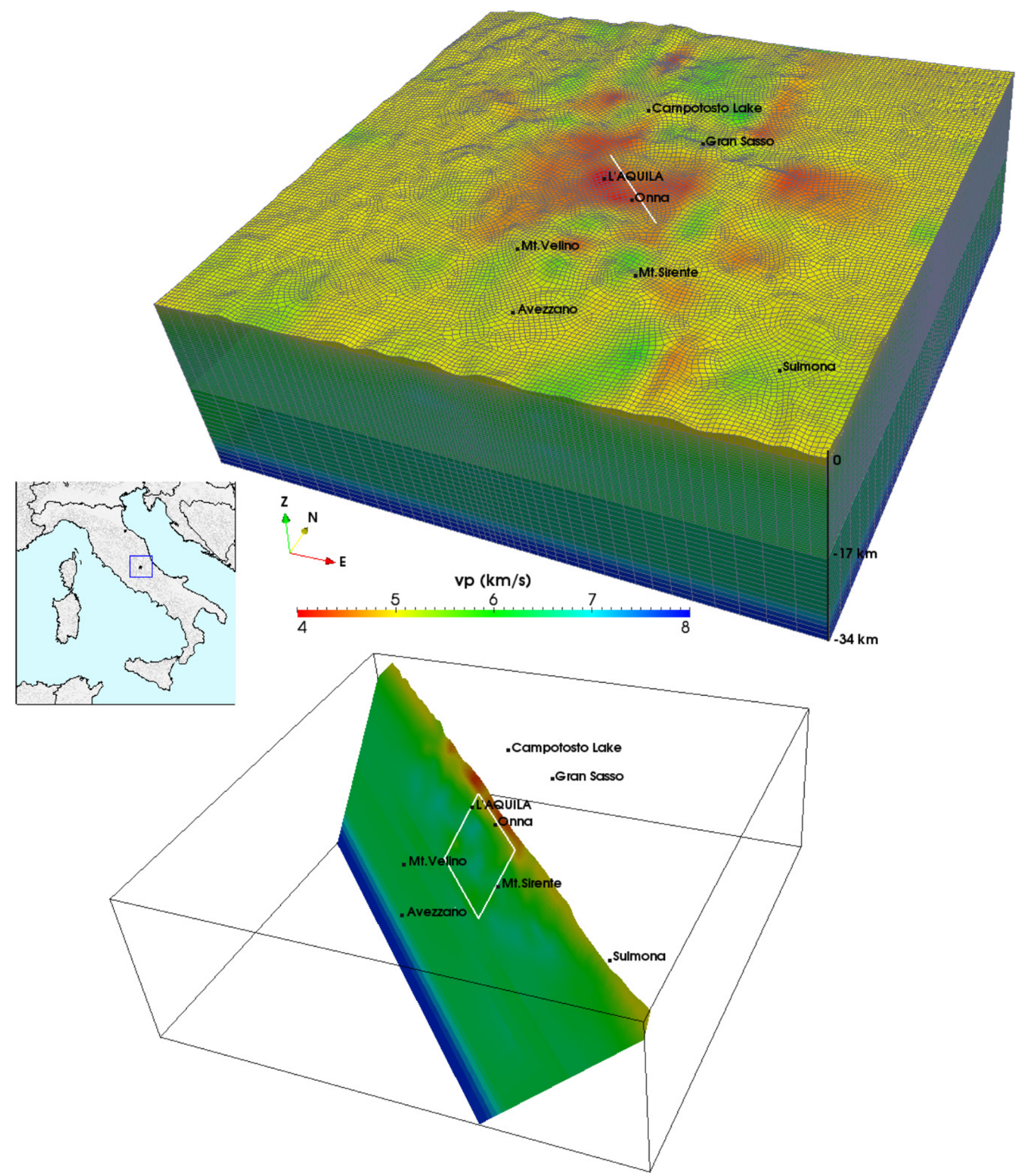

Figure 2. Image of the 3D simulation meshed volume with tomographic model included, viewed from SW. Topographic reliefs have been enhanced for a better visualization. The compressional wave velocity is shown in the whole domain (top figure) and on a section along the fault plane (bottom figure).

used, with $10 \mathrm{~km}$ horizontal resolution and $4 \mathrm{~km}$ vertical resolution. In the intermediate region, between 15 and $17 \mathrm{~km}$ depth, a grid resampling of the $16 \mathrm{~km}$ depth layer, present in both the considered velocity models, was performed and tomographic data were averaged, according to their resolution matrix.

We adopted the seismic source geometry proposed by Atzori and Antonioli [2011], where an original iterative algorithm is used to automatically retrieve the optimal fault subdivision in the linear inversion of coseismic data. The algorithm permits to obtain the best fault subdivision preserving, at the same time, the spatial resolution allowed by the data; this turns out to be a composition of patches with variable size, such that the model resolution matrix [Menke 1989] is as close as possible to the identity matrix. Within our computa- 
tional approach, the iterative splitting algorithm proposed by Atzori and Antonioli [2011] is not easily applicable, because each modification to the fault structure requires an interactive adjustment of the implemented source as well as the recalculation of the Green's function matrix at every step. However, the optimal patch subdivision is determined by the model resolution matrix, which ultimately depends on the particular dataset used in the inversion. Since in the present work we are using approximately the same datasets employed by Atzori and Antonioli [2011], we decided to implement in our FE model a fixed patch structure corresponding to their optimal solution. The resulting fault model is $24 \mathrm{~km} \times 18 \mathrm{~km}$ wide and is made up by 114 variable size patches, whose resolution noticeably decreases with depth: shallow patches result perfectly solved by data with very small dimensions, up to $0.28 \mathrm{~km} \times 0.19 \mathrm{~km}$, while at depth such a level of detail is not achievable and larger patches are produced by the adapting algorithm. This small patch size, especially at top of the fault, was the main reason for building the high-resolution mesh described before. Geometrical parameters of the fault are fixed: the strike and dip angles are $136^{\circ}$ and $50^{\circ}$ respectively, while the rake angle is $-100^{\circ}$, giving a minor right-lateral slip component.

\section{Methods}

Our FE approach has been thoroughly described and validated in previous studies, through a series of benchmark simulations on test cases [Volpe et al. 2007] as well as applications to real earthquakes [Volpe et al. $2011,2012]$. Here we will only briefly resume the basics of our modeling.

The FE simulations are carried out through an inhouse numerical simulation tool, FEMSA ("Finite Element Modeling for Seismic Applications"), basically a package composed by Fortran interface codes designed to embed faulting sources within an existing meshed domain and to set up and run the simulation. A more detailed description of the FEMSA features can be found in the user manual, available at http:/ / www. roma1.ingv.it/Members/volpe/manual.pdf. The bulk FE analysis [Dhondt 2004] is carried out by the CalculiX solver, a freely distributed 3D structural analysis software distributed under the terms of the GNU General Public License (http:/ / www.calculix.de).

To simulate the seismic source we exploited the equivalent body force theorem [Burridge and Knopoff 1964, Kanamori and Anderson 1975], by defining an appropriate distribution of double couples of forces on selected nodes to produce strains equivalent to dislocations. The strike and dip slip components are separately implemented and the total coseismic displacements are given by the superposition of the two simulations. Moreover, inhomogeneous boundary conditions are adopted, by constraining nodes on the bottom and lateral edges with analytically calculated displacements, obtained from the expressions derived by Okada $[1985,1992]$.

To retrieve the slip distribution on the variable patch fault, we performed a series of linear inversions of coseismic deformation data: we assigned a double couple of forces to each patch of the fault, in order to obtain the seismic moment associated with a unitary slip on the patch, and then used FE simulations to compute the Green's functions relating coseismic displacements to slip on each patch. Finally, we inverted the system $\underline{u}_{o b s}=$ $\mathcal{G} \times \underline{d}$, where $\underline{u}_{o b s}$ is the vector of the observed displacements, $\mathcal{G}$ is the Green's function matrix and $\underline{d}$ is the slip vector. We remark that in our approach the fault geometry must be fixed at the very first stage, as any variation of fault parameters would require the implementation of a different double couple distribution and the recalculation of the Green's function matrix, implying unfeasible computational time request.

The solution of the system is analytically obtained by means of the Damped Least Squares (DLS) method, according to the equation:

$$
\begin{aligned}
\underline{d}_{e s t}= & \underline{d}_{0}+\left(\mathcal{G}^{T} \cdot \mathcal{W} \cdot \mathcal{G}+k^{2} \cdot \mathcal{D}^{T} \cdot \mathcal{D}\right)^{-1} . \\
& \cdot \mathcal{G}^{T} \cdot \mathcal{W} \cdot\left(\underline{u}_{o b s}-\mathcal{G} \cdot \underline{d}_{0}\right),
\end{aligned}
$$

where $\underline{d}_{e s t}$ is the estimated slip vector, $\underline{d}_{0}$ is an arbitrary slip vector acting as initial condition (set as null slip condition; Volpe et al. [2012]), $\mathcal{W}$ is the data weight matrix, $k$ is an empirical coefficient [Menke 1989] and $\mathcal{D}$ the discrete approximation of the Laplacian operator.

The term $k^{2} \cdot \mathcal{D}^{T} \cdot \mathcal{D}$ is used to damp the singularity of the $\mathcal{G}$ matrix and regularize the inversion. The choice of the optimal damping term is a widely discussed subject of the inverse theory [Menke 1989, Amoruso et al. 2013]. An acceptable range of damping can be established through trade-off curves or L-curves [Boschi 2006, Cheloni et al. 2010]: the preferred solution should be chosen near the corner of the curve, but a visual analysis is not sufficient to individuate the point, since it is strongly dependent from the visualization scale and the exaggeration of the axes. We then followed the method proposed by Boschi [2006], calculating the curvature of each smoothing curve [Weisstein 2003] and selecting the solution model which corresponds to the maximum curvature. Such a method, as shown in a previous paper [Volpe et al. 2012], allows to unambiguously define the damping term, considering the fact that the inverted solution appears stable within 


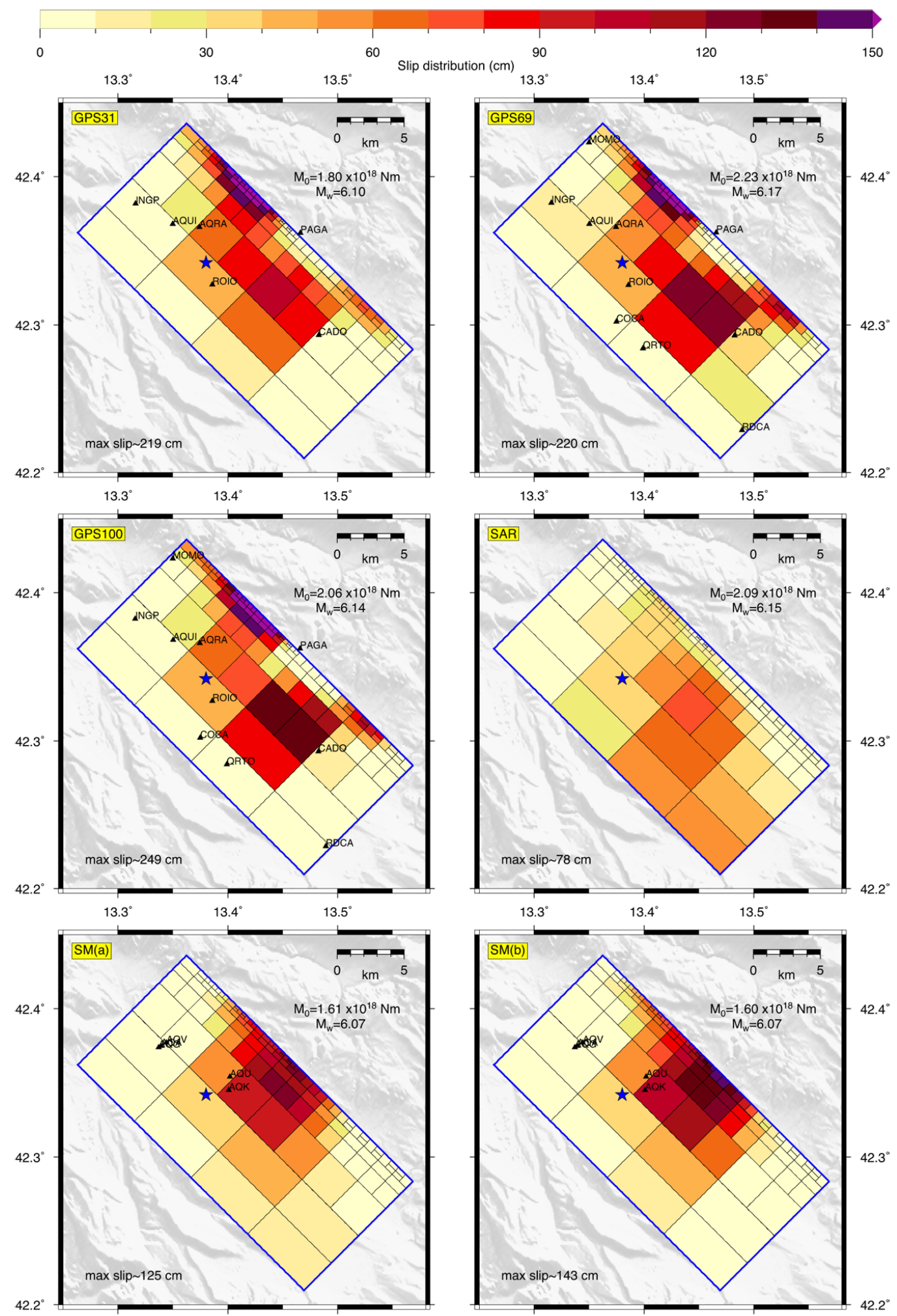

Figure 3. Source models obtained from the single inversions of GPS, InSAR and SM data. The seismic moment $\left(\mathrm{M}_{0}\right)$, the moment magnitude $\left(\mathrm{M}_{\mathrm{w}}\right)$ and the peak value of the slip release are shown. The blue star indicates the hypocenter. The GPS and SM stations contained within the surface projection of the fault are also displayed.

the neighbourhood of the preferred $k$ value. On the contrary, if the value of $k$ is too low, the smoothing term is negligible, resulting in non-physical spatial slip variations; if the $k$ value is too high, the smoothing term dominates and the estimated slip vector converges to the initial conditions [Volpe et al. 2012].
The use of multiple datasets requires an ad hoc weighting of the contributions. We faced this aspect by considering that GPS and SM static displacements have an almost diagonal variance matrix, i.e. a weak spatial correlation, while InSAR data are characterized by a full variance/covariance matrix. In other words, the weight 
matrix $\mathcal{W}$ related to GPS and SM offsets is derived on the basis of the reported measurement uncertainties, while InSAR data are weighted according to the variance-covariance matrix obtained from L-, X- and Cband interferograms with only atmospheric artifacts. In such a way, assuming that every geodetic technique is measuring the same displacement field, the contributions of the datasets are balanced in a weighted linear inversion strategy and this allows to compensate the different density and accuracy of each geodetic dataset.

Finally, a positivity constraint was imposed, in order to avoid unrealistic back-slip values. The positivity constraint does not affect the overall slip pattern, whose main features are preserved with or without the constraint.

\section{Inversion results}

GPS and InSAR data were separately inverted and the inferred slip distributions on the fault are shown in Figure 3. For the sake of completeness, static displacements from SM data were also separately inverted (Figure 3), but the very small number of data makes such inversions not completely reliable. Then, joint inversions were performed, as shown in Figures 4-6. The model-data GPS and SM vector fits for each inversion involving GPS and/or SM datasets are separately provided in the supporting material (Figures S2-S11 for GPS displacements and S12-S17 for SM offsets). Similarly, also the observed and modeled InSAR deformations and the correspondent residuals are displayed in Figures S18 and S19, respectively.

The statistical analysis of the model misfit with respect to the measured offsets is given in Table 4 in terms of root mean squares (RMS) of residuals, defined as:

$$
R M S=\sqrt{\frac{\sum_{i}^{N}\left(u_{i, \text { mod }}-u_{i, o b s}\right)^{2}}{N}},
$$

where $N$ is the number of measurements, while $u_{i, \bmod }$ and $u_{i, o b s}$ are the modeled and the observed deformations.

The estimated rupture model is quite stable for all of the separate or joint inversions involving GPS data. In fact, these infer a slip distribution featured by two maximum slip patches. The main patch is located SE of the hypocenter and is similar to the asperity found by Atzori and Antonioli [2011] as their best solution with the same fault plane, although they considered a simple half-space model. A second shallow and smaller slip patch, absent in Atzori and Antonioli [2011], is situated up-dip of the hypocenter and reaches the top of the fault, very close to the surface. This appears in contrast with our results from a previous work [Volpe et al.
2012], where the inversion of GPS data on a coarser 3D FE mesh, using a source model subdivided in regular patches $2 \mathrm{~km} \times 2 \mathrm{~km}$ sized, produced a well-localized slip pattern, with a single high-slip area SE of the hypocenter. On the other hand, the model retrieved from InSAR and InSAR+SM inversions in the present work lacks in the shallow high slip patch too, turning out to be quite similar to the previously published models [Volpe et al. 2012]. The inversion of the coseismic offsets from SM data produces an unexpectedly reasonable slip pattern, in spite of the poor population of the dataset, which exhibits a single patch consistent with the observed main patch but shifted NE and extending to the top of the fault, towards the area of the second small patch.

In the following, the obtained slip patterns will be described in detail, but we will no further discuss the separate SM inversion, since that dataset is not enough dense to give reliable results.

The inversions of the GPS data are considerably stable, producing slip distributions on the fault which appear quite similar, especially when results from GPS69 and GPS100 inversions are considered. Incidentally, a test inversion was carried out on the old GPS17 dataset from Volpe et al. [2012] with consistent results. In all of the inferred models (Figure 3), the shallow patch lo-

\begin{tabular}{|c|c|c|c|}
\hline Dataset & GPS & SAR & SM \\
\hline GPS31 & 2.0 & - & - \\
\hline GPS69 & 5.5 & - & - \\
\hline GPS100 & 4.6 & - & - \\
\hline SAR & - & 2.1 & - \\
\hline SAR+GPS31 & 1.8 & 2.3 & - \\
\hline SAR+GPS69 & 5.5 & 2.4 & - \\
\hline SAR+GPS100 & 4.7 & 2.4 & - \\
\hline $\mathrm{GPS} 31+\mathrm{SM}(a)$ & 2.1 & - & 3.2 \\
\hline $\mathrm{GPS} 31+\mathrm{SM}(b)$ & 2.1 & - & 2.2 \\
\hline GPS69+SM(a) & 5.5 & - & 3.6 \\
\hline GPS69+SM(b) & 5.5 & - & 2.7 \\
\hline $\operatorname{GPS} 100+\operatorname{SM}(a)$ & 4.7 & - & 3.7 \\
\hline $\mathrm{GPS} 100+\mathrm{SM}(b)$ & 4.7 & - & 2.6 \\
\hline $\mathrm{SAR}+\mathrm{SM}(a)$ & - & 2.2 & 3.1 \\
\hline $\mathrm{SAR}+\mathrm{SM}(b)$ & - & 2.2 & 2.5 \\
\hline $\mathrm{SAR}+\mathrm{GPS} 100+\mathrm{SM}(b)$ & 4.9 & 2.4 & 2.8 \\
\hline
\end{tabular}

Table 4. RMS of residuals between observed and modeled coseismic displacements obtained from the linear inversion of observed data. For the joint inversions, the RMS was computed with respect to each dataset separately. RMS is in units of $\mathrm{cm}$. 
cated at the top of the fault, up-dip of the hypocenter, is present, with very high peak values, greater than $2 \mathrm{~m}$. This slip patch starts at about $4 \mathrm{~km}$ from the NW edge of the fault and extends in the $S E$ direction for about $5 \mathrm{~km}$, reaching a depth of about $2 \mathrm{~km}$ along-dip. The main high slip area, located SE of the hypocenter, appears more concentrated when the GPS69 and GPS100 datasets are inverted: in these cases, the patch starts at about $12 \mathrm{~km}$ from the NW edge of the fault at a depth of $4.5 \mathrm{~km}$ (along-dip) and extends in the SE direction and downdip, spanning about $50 \mathrm{~km}^{2}$ on the fault plane. The maximum slip value on the patch is about $130-140 \mathrm{~cm}$. In the GPS31 inversion the pattern is similar, but the patch appears more spread in the NW direction and reaches a lower value of maximum slip release, equal to $105 \mathrm{~cm}$. This inversion, involving the less populated GPS dataset, results in the lowest value of the misfit between observed and modeled deformation $(2 \mathrm{~cm})$, with respect to RMS derived from GPS69 and GPS100 inversions ( 5.5 and $4.6 \mathrm{~cm}$, respectively). As a final remark, in all of the retrieved slip models the SE portion of the fault plane turns out to be not affected by the rupture process, apart from a small shallow patch which is present in these patterns but disappears in the subsequent InSAR and joint inversions, and no slip release is obtained SE of the CADO GPS site.

The inversion of InSAR data (Figure 3) produces a slip distribution on the fault plane which, although consistent with results from GPS inversions, appears more spread along the SE portion of the rupture plane, with a slip peak value equal to $78 \mathrm{~cm}$, definitely much lower than maximum slip values observed within the previous models retrieved from GPS inversions. On the contrary, the seismic moment corresponding to this distribution is comparable with values obtained from GPS inversions. It must be remarked that the main difference is the absence of the small shallow patch in the NE area of the fault, where in the other cases there is a significant slip concentration. Incidentally, one of the reasons of the presence of the two almost equipotential minima in the solution space could be an incomplete compatibility of the presently available geodetic datasets, as the different solutions obtained by single inversions apparently suggest.

The slip distribution on the fault observed when GPS and InSAR deformations are jointly inverted (Figure 4) is more similar to the pattern retrieved from GPS inversion than to the one from InSAR inversion, despite of the great number of interferometric data with respect to GPS. This can be ascribed to the weighting data matrix $\mathcal{W}$ introduced in the inversion (Equation 1), where the GPS related terms have a very low uncertainty, while InSAR data show strong covariance values because of the well-known spatial correlation. As a consequence, the same key features previously described can be observed, that is two slip concentrations, located SE and up-dip of the hypocenter, and the absence of slip release SE of the CADO site. We note that in the models obtained from joint inversions the shallow patch is less extended with respect to the separate GPS inversion results, producing a less relevant slip concentration, with peak values well below $2 \mathrm{~m}(\sim 130-170 \mathrm{~cm})$. Moreover, the total moment release is also lower.

The models obtained from the joint inversion of GPS and SM displacements are shown in Figure 5. No relevant differences with respect to the GPS inversions of Figure 3 can be appreciated, but it is worth noting that the lowest misfits for SM data are obtained with the $\mathrm{SM}(b)$ dataset (Table 4). Similarly, the joint InSAR+SM inversions, displayed at the bottom of Figure 4, resemble the InSAR inversion (Figure 3), but in such a case the SM contribution appears more evident as the slip distribution is more concentrated, with peak values slightly higher $(98$ and $105 \mathrm{~cm}$ ) but still lower than maximum slip obtained from the other inversions. Moreover, a rough shallow slip patch appears up-dip of the hypocenter, although the released slip does not exceed $60 \mathrm{~cm}$. Also in this case, the $\mathrm{SM}(b)$ dataset is better fitted. Definitely, the SM dataset turns out to play a minimal role in these inversions, as expected due to the small number of data, but the retrieved slip patterns seem to support the hypothesis of a two patch slip pattern.

Finally, in Figure 6 we show the model retrieved from the inversion of the most complete available dataset, that is InSAR+GPS100+SM(b) (using SM(a) produces no differences). This global inversion confirms the slip pattern featured by two high slip patches, SE and up-dip of the hypocenter. In fact, the pattern is comparable to results observed from the joint inversion of the geodetic data, i.e. InSAR and GPS100, but the moment release and especially the maximum slip value are lower. The distribution appears more concentrated, with two well defined patches.

\section{Discussion}

The present study focuses the attention on two different configurations within the investigated inversion domain, i.e. a single- and a double-patch slip distribution, which appear to be two almost equally likely solutions for the rupture model. The improvement of the 3D FE model with respect to our previous work [Volpe et al. 2012] as well as the uneven subdivision of the faulting source allowed us to highlight such a discrepancy: the higher resolution, especially for shallow patches, brought us to accomplish a higher level of detail with respect to the old model. The same ambiguity 


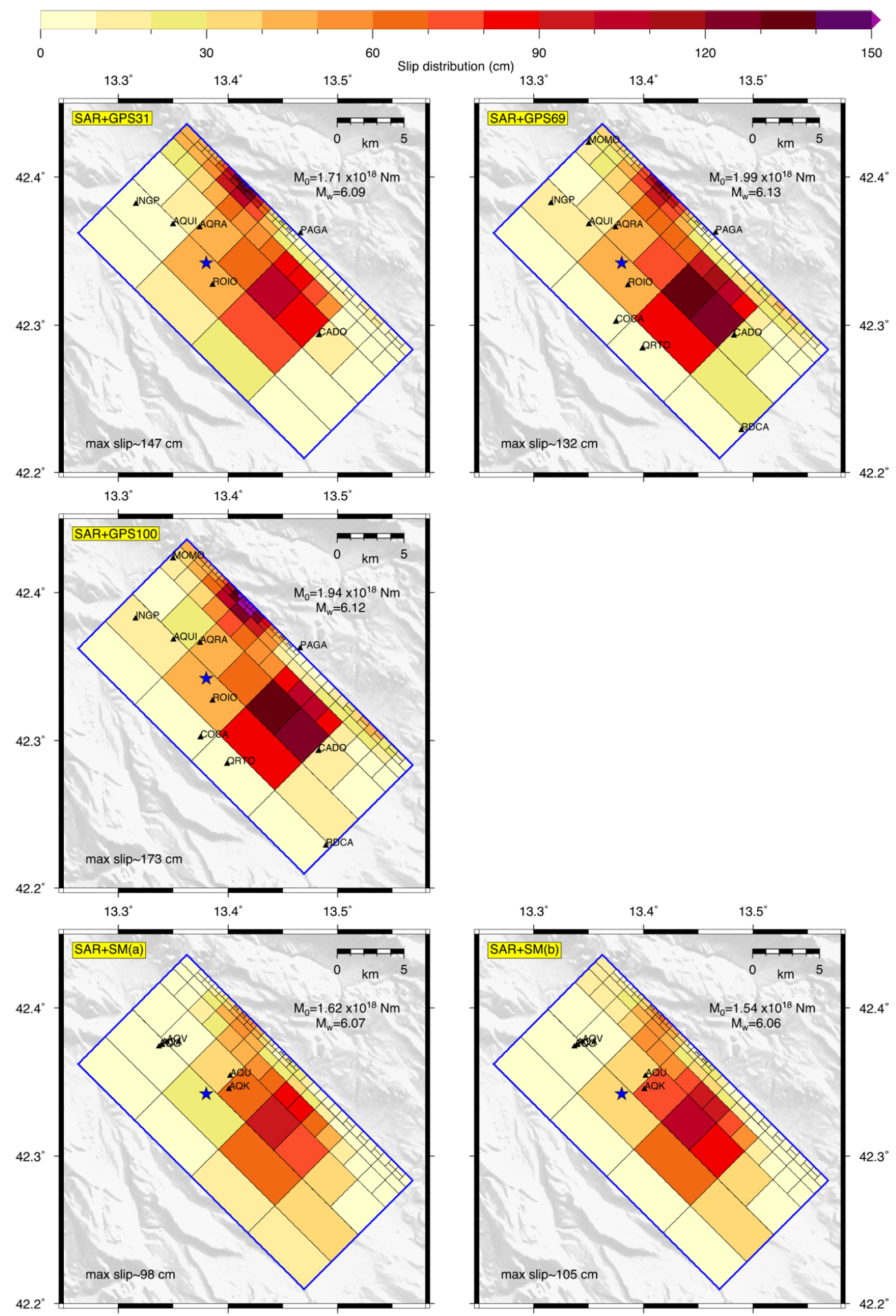

Figure 4. Same as Figure 3 but from joint inversions of InSAR with GPS or SM data.

is also found by comparing results from different authors, where a single slip patch model [Walters et al. 2009, Trasatti et al. 2011, Serpelloni et al. 2012] or two slip patches [Cirella et al. 2009, Cheloni et al. 2010, Scognamiglio et al. 2010, Cirella et al. 2012] are obtained. We remark that the algorithm used to subdivide the fault plane produces the most important refinement of the source just in the area of the second high slip patch. Incidentally, we note that the fault zone structure revealed several geometrical complexities: Valoroso et al. [2014], by using high-resolution earthquake distribution, recently proposed a picture of the fault zone where a conjugate system of synthetic and antithetic normal faults is found at shallow depth. In particular, in the same area of the ambiguous slip patch, sequence relocations suggest the presence of a second- 


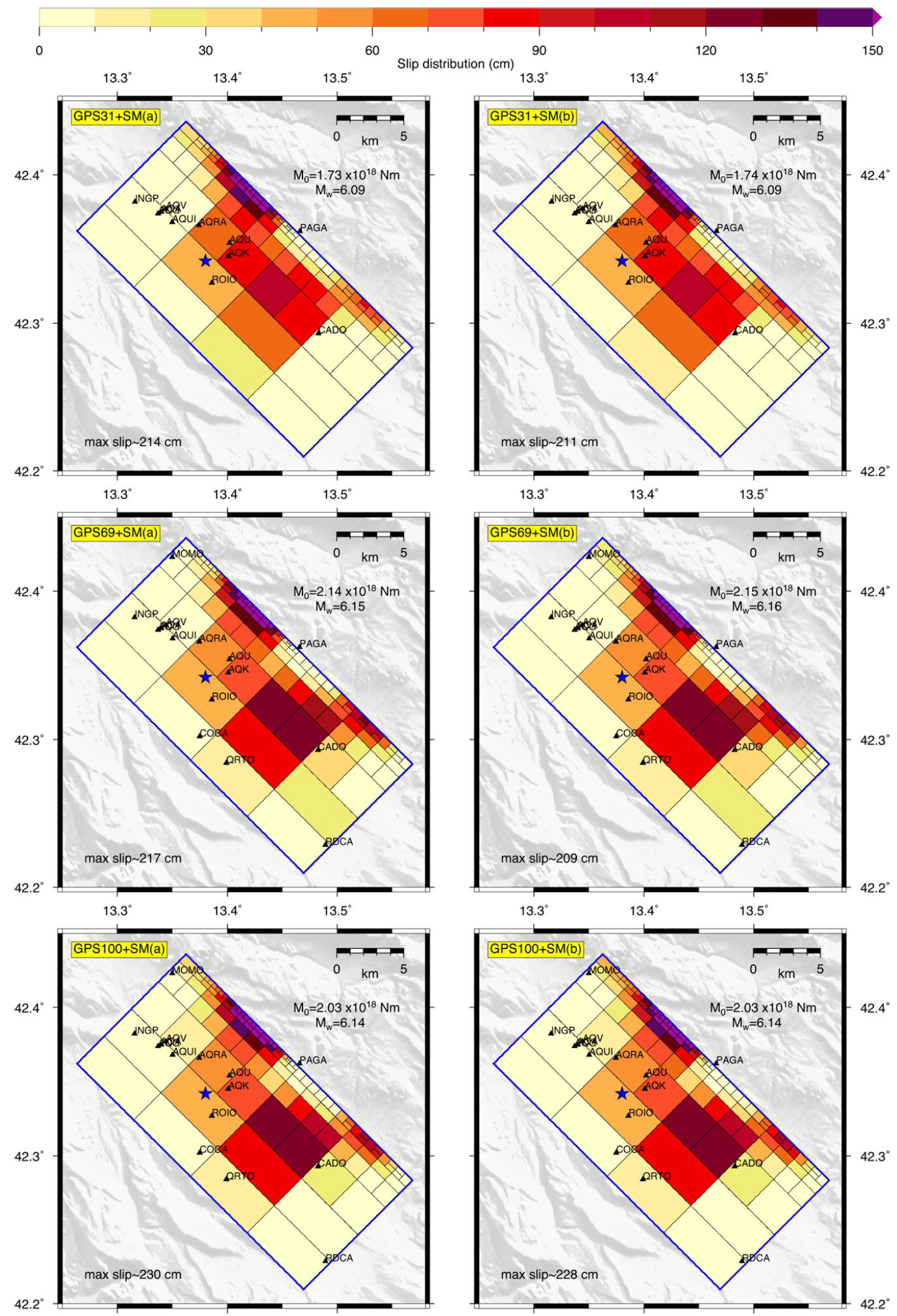

Figure 5. Same as Figure 3 but from joint inversions of GPS and SM data.

ary antithetic segment close to the principal fault trace [Valoroso et al. 2014], evidencing an overall complexity affecting that area. Moreover, the inspected strong dependence of the obtained slip distributions from the model as well as from the inverted dataset is crucial, since it suggests the inability of presently available observational datasets and numerical models of definitively solving the widely debated issue concerning the slip release at the top of the fault responsible for the L'Aquila earthquake.

As from numerical modeling, two different scenarios are also deduced when geological or seismological analysis are considered.

Geological field surveys within the epicentral area agree in observing continuous coseismic surface ruptures for about $3 \mathrm{~km}$ along the northern portion of the 


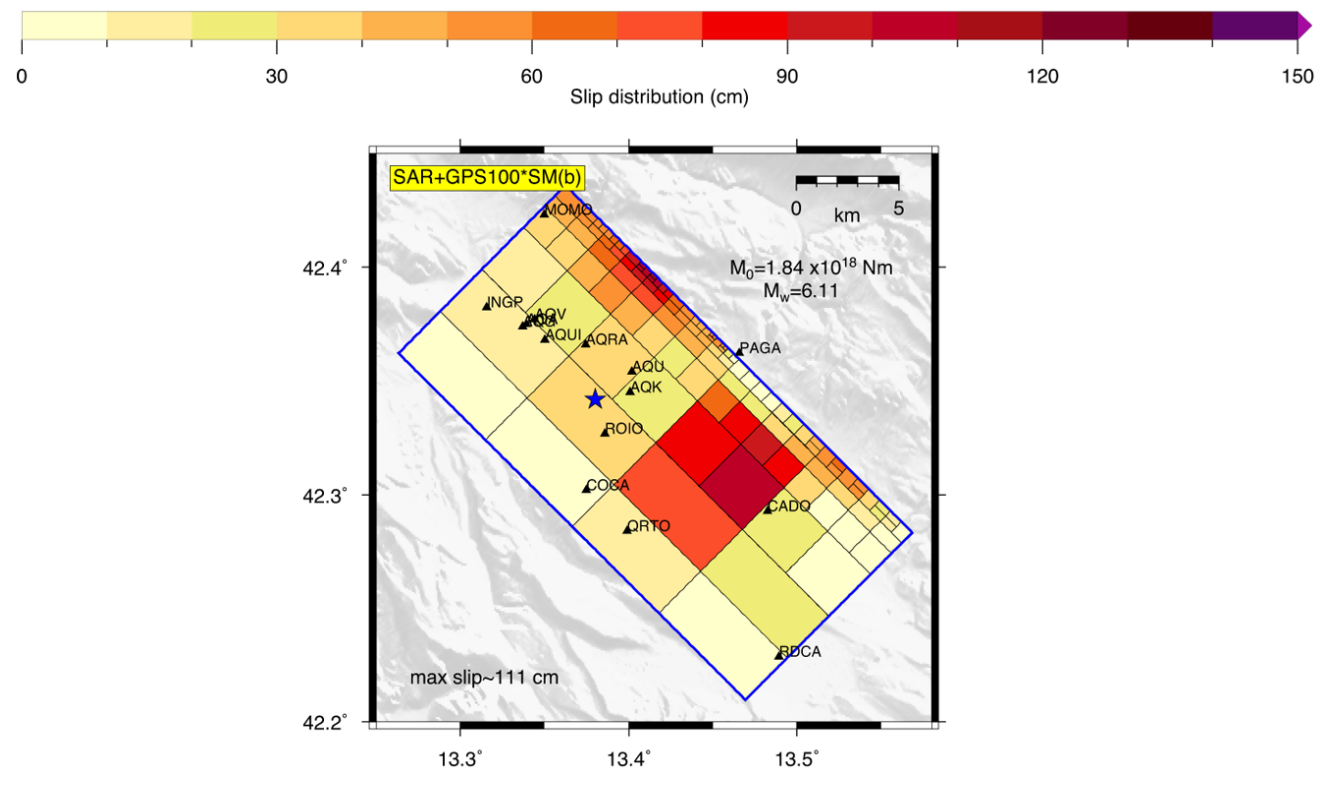

Figure 6. Same as Figure 3 but from the joint inversion of the most complete dataset, namely InSAR, GPS100 and SM.

Paganica fault trace accompanied by more sparse and faint ground ruptures that extend both to the NW and to the SE. EMERGEO Working Group [2010] and Vittori et al. [2011] interpreted the $3 \mathrm{~km}$-long coseismic ruptures as the only surface expression of the seismogenic source (i.e. primary surface faulting), originating from the propagation to the surface of the slip at depth on the rupture plane. This is consistent with the main slip patch located SE of the hypocenter. The minor ground fractures are interpreted as due to sympathetic slip or shaking effect. In contrast, other authors [Boncio et al. 2010, Galli et al. 2010, Gori et al. 2012] also include the discontinuous ruptures as direct evidence of coseismic slip on the causative fault, thus extending NW and SE the total length of primary surface faulting up to $10-19 \mathrm{~km}$. In this case, the retrieved small shallow slip patch appears consistent with such observations.

The analysis of seismological data seems to support the two slip patch model, as two distinct stages in the rupture history are suggested: the rupture onset appears characterized by slip concentration up-dip of the hypocenter, followed by the along-strike propagation and the failure of the deep slip patch [Di Stefano et al. 2011, Cirella et al. 2012]. On the contrary, the study of the seismicity evolution from permanent and temporary seismic networks by Chiarabba et al. [2009] resulted in the lack of slip in the upper portion of the fault, corroborating the pattern featured by a single deep slip patch on the rupture plane.

\section{Conclusions}

We investigated the rupture slip distribution for the 2009 L'Aquila main shock by adopting a complex high-resolution 3D FE model incorporating surface to- pography and rheological heterogeneities, deduced from real tomography. Moreover, we implemented a recently proposed source model consisting in a variable patch fault plane, in order to achieve a detailed information of the slip release on the rupture plane.

We computed the Green's functions by means of 3D FE simulations and built up a procedure to use the synthetic displacements in a linear inversion scheme of coseismic deformation data (GPS, InSAR and SM). We inverted for the slip through the DLS method, first considering datasets separately and then performing the joint inversions.

The most observed trend in this study exhibits a slip distribution on the fault featured by two slip concentrations, located SE and up-dip of the hypocenter. This result differs from our previous study [Volpe et al. 2012], where the inversion of GPS data, using a coarser FE model and a regular less-detailed patch source model, produced a fully localized slip pattern, evidencing a single high slip area SE of the hypocenter. In our opinion, even if the most advanced and complete simulations slightly favours the two patch solution, nevertheless the two configurations turn out to be almost equivalent within the investigated inversion domain, which can not be univocally solved by available deformation data. We restate that the $3 \mathrm{D}$ modeling including real Earth complexities and the adoption of a heterogeneous faulting source allowed us to highlight this ambiguity. Moreover, the overall compatible but different results, again in terms of one or two high slip patches, obtained inverting GPS and InSAR data separately could reveal a lack of robustness and reliability in one or both of the observational datasets.

In conclusion, regardless of the analysed observ- 
ables and the adopted approach (coseismic deformation numerical modeling, geological and seismological investigations), the investigated inversion domain appears inherently characterized by two almost equipotential solutions. The two high-slip patch rupture model seems slightly more convincing, also considering the geometrical complexities affecting the area of the debated slip release [Valoroso et al. 2014], but, from our study, it is clear that the available observational datasets and numerical models are not able to univocally discriminate between the two scenarios. These have significantly different impact in terms of seismic hazard assessment, as the presence of the shallow patch would affect the strong motion pattern of the interested area, and for the sake of caution both scenarios should be considered in seismic hazard assessments.

The L'Aquila earthquake belongs to a long seismic sequence which started at the end of 2008 and continued during the subsequent months after April 6th. In fact, the largest release of energy resulted in the first few days after the main shock, with the occurrence of few events having magnitude $M_{w} \geq 5$. Consequently, the coseismic displacements, estimated from the different techniques across that period, account for a cumulative effects of those large events. Given such complexity, future work could be devoted to develop a linked fault model taking into account the major ruptures besides the main shock.

Acknowledgements. The authors are grateful to the CalculiX and Cubit developers for the continual software development and upgrading. We thank Dr. S. Pucci for the useful discussion about geological interpretations and Dr. A. Avallone and Dr. C. Di Alessandro for sharing partially unpublished data.

\section{References}

Amoruso, A., S. Barba, L. Crescentini and A. Megna (2013). Inversion of synthetic geodetic data for dipslip faults: clues to the effects of lateral heterogeneities and data distribution in geological environments typical of the Apennines (Italy), Geophys. J. Int., 192, 745-758; doi:10.1093/gji/ggs042.

Anzidei, M., E. Boschi, V. Cannelli, R. Devoti, A. Esposito, A. Galvani, D. Melini, G. Pietrantonio, F. Riguzzi, V. Sepe and E. Serpelloni (2009). Coseismic deformation of the destructive April 6, 2009 L'Aquila earthquake (central Italy) from GPS data, Geophys. Res. Lett., 36, L17307; doi:10.1029/2009GL039145.

Atzori, S., I. Hunstad, M. Chini, S. Salvi, C. Tolomei, C. Bignami, S. Stramondo, E. Trasatti, A. Antonioli and E. Boschi (2009). Finite fault inversion of DInSAR coseismic displacement of the 2009 L'Aquila earthquake (central Italy), Geophys. Res. Lett., 36, L15305; doi:10.1029/2009GL039293.
Atzori, S., and A. Antonioli (2011). Optimal fault resolution in geodetic inversion of coseismic data, Geophys. J. Int., 185, 529-538; doi:10.1111/j.1365-246X. 2011.04955.x.

Avallone, A., M. Marzario, A. Cirella, A. Piatanesi, A. Rovelli, C. Di Alessandro, E. D’Anastasio, N. D’Agostino, R. Giuliani and M. Mattone (2011). Very high rate $(10 \mathrm{~Hz})$ GPS seismology for moderate-magnitude earthquakes: The case of the Mw 6.3 L'Aquila (central Italy) event, J. Geophys. Res., 116, B02305; doi:10.1029/2010JB007834.

Beutler, G., et al. (2007). Bernese GPS software, edited by R. Dach et al., Astron. Inst., Univ. of Bern, Bern.

Blewitt, G. (2008). Fixed point theorems of GPS carrier phase ambiguity resolution and their application to massive network processing: Ambizap, J. Geophys. Res., 113, B12410; doi:10.1029/2008JB005736.

Boncio, P., A. Pizzi, F. Brozzetti, G. Pomposo, G. Lavecchia, D. Di Naccio and F. Ferrarini (2010). Coseismic ground deformation of the 6 April 2009 L'Aquila earthquake (central Italy, Mw 6.3), Geophys. Res. Lett., 37, L06308; doi:10.1029/2010GL042807.

Boschi, E., E. Guidoboni, G. Ferrari, D. Mariotti, G. Valensise and P. Gasperini (2000). Catalogue of strong Italian earthquakes from 461 B.C. to 1997, Annali di Geofisica, 43, 609-868.

Boschi, L. (2006). Global multiresolution models of surface wave propag comparing equivalently regularized Born and ray theoretical solutions, J. Geophys. Res., 167, 238-252; doi:10.1111/j.1365-246X.2006. 03084.x.

Burridge, R., and L. Knopoff (1964). Body force equivalents for seismic dislocations, B. Seismol. Soc. Am., 54, 1875-1888.

Casarotti, E., M. Stupazzini, S.J. Lee, D. Komatitsch, A. Piersanti and J. Tromp (2008). CUBIT and Seismic Wave Propagation Based Upon the Spectral-element Method: An Advanced unstructured Mesher for Complex 3D Geological Media, In: M.L. Brewer and D. Marcum (eds.), Proceedings of the 16th International Meshing Roundtable, Springer, New York, (session 5B) 579-597; doi:10.1007/978-3-54075103-8 32.

Cheloni, D., N. D’Agostino, E. D’Anastasio, A. Avallone, S. Mantenuto, R. Giuliani, M. Mattone, S. Calcaterra, P. Gambino, D. Dominici, F. Radicioni and G. Fastellini (2010). Coseismic and initial post-seismic slip of the $M_{w} 6.3$ L'Aquila earthquake, Italy, from GPS measurements, Geophys. J. Int., 181, 1539-1546.

Chiarabba, C., et al. (2009). The 2009 L'Aquila (central Italy) $\mathrm{M}_{\mathrm{W}} 6.3$ earthquake: Main shock and aftershocks, Geophys. Res. Lett., 36, L18308; doi:10.102 
9/2009GL039627.

Chiarabba, C., I. Bianchi, S. Bagh, P. De Gori and M. Barchi (2010). Deep structural heterogeneities and the tectonic evolution of the Abruzzi region (central Apennines, Italy) revealed by microseismicity, seismic tomography, and teleseismic receiver functions, Earth Plan. Sci. Lett., 295, 462-476.

Cirella, A., A. Piatanesi, M. Cocco, E. Tinti, L. Scognamiglio, A. Michelini, A. Lomax and E. Boschi (2009). Rupture history of the 2009 L'Aquila (Italy) earthquake from non-linear joint inversion of strong motion and GPS data, Geophys. Res. Lett., 36, L19304; doi:10.1029/2009GL039795.

Cirella, A., A. Piatanesi, E. Tinti, M. Chini and M. Cocco (2012). Complexity of the rupture process during the 2009 L'Aquila, Italy, earthquake, Geophys. J. Int., 190, 607-621; doi:10.1111/j.1365-246X.2012.055 05.x.

Covellone, B.M., and B. Savage (2012). A Quantitative Comparison between 1D and 3D Source Inversion Methodologies: Application to the Middle East, B. Seismol. Soc. Am., 102 (5), 2189-2199; doi:10.1785/ 0120110278.

Devoti, R., L. Anderlini, M. Anzidei, A. Esposito, A. Galvani, G. Pietrantonio, A.R. Pisani, F. Riguzzi, V. Sepe and E. Serpelloni (2012). The coseismic and postseismic deformation of the L'Aquila, 2009 earthquake from repeated GPS measurements, Ital. J. Geosci., 131 (3), 348-358; doi:10.3301/IJG.2012.15. Dhondt, G. (2004). The Finite Element Method for Three-Dimensional Thermomechanical Applications, Wiley.

Di Stefano, R., C. Chiarabba, L. Chiaraluce, M. Cocco, P. De Gori, D. Piccinini and L. Valoroso (2011). Fault zone properties affecting the rupture evolution of the 2009 (Mw 6.1) L'Aquila earthquake (central Italy): Insights from seismic tomography, Geophys. Res. Lett., 38, L10310; doi:10.1029/2011GL047365.

Dziewonski, A.M., T.A. Chou and J.H. Woodhouse (1981). Determination of earthquake source parameters from waveform data for studies of global and regional seismicity, J. Geophys. Res., 86 (B4), 28252852; doi:10.1029/JB086iB04p02825.

EMERGEO Working Group (2010). Evidence for surface rupture associated with the $\mathrm{M}_{\mathrm{w}} 6.3 \mathrm{~L}$ 'Aquila earthquake sequence of April 2009 (central Italy), Terra Nova, 22, 43-51; doi:10.1111/j.1365-3121.2009. 00915.x.

Farr, T.G., P.A. Rosen, E. Caro, R. Crippen, R. Duren, S. Hensley, M. Kobrick, M. Paller, E. Rodriguez, L. Roth, D. Seal, S. Shaffer, J. Shimada, J. Umland, M Werner, M. Oskin, D. Burbank and D. Alsdorf (2007). The Shuttle Radar Topography Mission, Rev. Geophys.,
45 (2); doi:10.1029/2005RG000183.

Galli, P., B. Giaccio and P. Messina (2010). The 2009 central Italy earthquake seen through 0.5 Myr-long tectonic history of the L'Aquila faults system, Quaternary Science Reviews, 29, 3768-3789.

Gori, S., E. Falcucci, S.Atzori, M. Chini, M. Moro, E. Serpelloni and G. Fubelli (2012). Constraining primary surface rupture length along the Paganica fault (2009 L'Aquila earthquake) with geological and geodetic (DInSAR and GPS) data, Ital. J. Geosci., 131 (3), 359-372; doi:10.3301/IJG.2012.21.

Herring, T., R.W. King and S. McClusky (2006). GAMIT Reference Manual, Release 10.3, Massachussetts Institute of Technology, Cambridge, MA.

Kanamori, H., and D.L. Anderson (1975), Theoretical basis of some empirical relations in seismology, B. Seismol. Soc. Am. 65, 1073-1095.

Komatitsch, D., Q. Liu, J. Tromp, P. Suss, C. Stidham and J.H. Shaw (2004). Simulations of Ground Motion in the Los Angeles Basin Based upon the Spectral-Element Method, B. Seismol. Soc. Am., 94 (1), 187-206.

Magnoni, F., E. Casarotti, A. Michelini, A. Piersanti, D. Komatitsch, D. Peter and J. Tromp (2014). SpectralElement Simulations of Seismic Waves Generated by the 2009 L'Aquila Earthquake, B. Seismol. Soc. Am., 104 (1), 73-94; doi:10.1785/0120130106.

Menke, W. (1989). Geophysical data analysis: discrete inverse theory, International Geophysics Series, vol. 45, Academic Press, Inc., San Diego, California.

Mothag, M., J. Klotz, F. Tavakoli, Y. Djamour, S. Arabi, H.U. Wetzel and J. Zschau (2006). Combination of precise leveling and InSAR data to constrain source parameters of the $\mathrm{Mw}=6.5$, 26 December $2003 \mathrm{Bam}$ earthquake, Pure Appl. Geophys., 163 (1), 1-18.

Okada, Y. (1985). Surface deformation due to shear and tensile faults in a half-space, B. Seismol. Soc. Am., 75, 1135-1154.

Okada, Y. (1992). Internal deformation due to shear and tensile faults in a half-space, B. Seismol. Soc. Am., 82, 1018-1040.

Paolucci, R., A. Rovelli, E. Faccioli, C. Cauzzi, D. Finazzi, M. Vanini, C. Di Alessandro and G. Calderoni (2008). On the reliability of long-period response spectral ordinates from digital accelerograms, Earthquake Engng Struct. Dyn., 37: 697-710; doi:10. 1002 / eqe. 781 .

Pondrelli, S., S. Salimbeni, A. Morelli, G. Ekström, M. Olivieri and E. Boschi (2010). Seismic moment tensors of the April 2009, L'Aquila (Central Italy) earthquake sequence, Geophys. J. Int., 180, 238-242.

Scognamiglio, L., E. Tinti, A. Michelini, D. Dreger, A. Cirella, M. Cocco, S. Mazza and A. Piatanesi (2010). 
Fast Determination of Moment Tensors and Rupture History: what has been learnt from the April 6th 2009, L'Aquila Earthquake Sequence, Seismol. Res. Lett., 81 (6), 892-906; doi:10.1785/gssrl.81.6.892.

Serpelloni, E., L. Anderlini and M.E. Belardinelli (2012). Fault geometry, coseismic-slip distribution and Coulomb stress change associated with the 2009 April 6, Mw 6.3, L'Aquila earthquake from inversion of GPS displacements, Geophys. J. Int, 188, 473-489; doi:10.1111/j.1365-246X.2011.05279.x.

Simons, M., Y. Fialko and L. Rivera (2002). Coseismic Deformation from the $1999 \mathrm{Mw}$ 7.1 Hector Mine, California, Earthquake as Inferred from InSAR and GPS Observations, Bull. Seismol. Soc. Am., 92, 1390-1402.

Stramondo, S., M. Chini, C. Bignami, S. Salvi and S. Atzori (2011). X-, C-, and L-band DInSAR investigation of the April 6, 2009, Abruzzi earthquake, IEEE Geosci. Rem. Sens. Lett., 8 (1); doi:10.1109/LGRS. 2010.2051015.

Trasatti, E., C. Kyriakopoulos and M. Chini (2011). Finite element inversion of DInSAR data from the Mw 6.3 L’Aquila earthquake, 2009 (Italy), Geophys. Res. Lett., 38, L08306; doi:10.1029/2011GL046714.

Valoroso, L., L. Chiaraluce and C. Collettini (2014). Earthquakes and fault zone structure, Geology; doi:10.1130/G35071.1.

Vittori, E., P. Di Manna, A.M. Blumetti, V. Comerci, L. Guerrieri, E. Esposito, A.M. Michetti, S. Porfido, L. Piccardi, G.P. Roberts, A. Berlusconi, F. Livio, G. Sileo, M. Wilkinson, K.J.W. McCaffrey, R.J. Phillips and P.A. Cowie (2011). Surface Faulting of the 6 April 2009 Mw 6.3 L'Aquila Earthquake in Central Italy, B. Seismol. Soc. Am., 101 (4), 1507-1530; doi:10. $1785 / 0120100140$.

Volpe, M., D. Melini and A. Piersanti (2007). FEMSA: A finite element simulation tool for quasi-static deformation modeling, Annals of Geophysics, 50, 367-385.

Volpe, M., D. Melini and A. Piersanti (2011). Trade-Off Between Seismic Source Detail and Crustal Heterogeneities in Spherical 3D Finite Element Modeling: the 2004 Sumatra Earthquake case-study, Annals of Geophysics, 54 (1), 91-103.

Volpe, M., A. Piersanti and D. Melini (2012). Complex 3-D Finite Element modelling of the 2009 April 6 L'Aquila earthquake by inverse analysis of static deformation, Geophys. J. Int, 188, 1339-1358; doi:10.11 11/j.1365-246X.2011.05330.x.

Walters, R.J., J.R. Elliott, N. D’Agostino, P.C. England, I. Hunstad, J.A. Jackson, B. Parsons, R.J. Phillips and G. Roberts (2009). The 2009 L'Aquila earthquake (central Italy): A source mechanism and implications for seismic hazard, Geophys. Res. Lett., 36, L17312;
doi:10.1029/2009GL039337.

Weisstein, E.W. (2003). CRC Concise Encyclopedia of Mathematics, Chapman \& Hall/CRC, Boca Raton, Florida.
Corresponding author: Manuela Volpe, Istituto Nazionale di Geofisica e Vulcanologia, Rome, Italy; email: manuela.volpe@ingv.it.

C 2015 by the Istituto Nazionale di Geofisica e Vulcanologia. All rights reserved. 